Int. J. Electrochem. Sci., 14 (2019) 9741 - 9754

\title{
Experimental research on the counter-rotating electrochemical machining of 304 stainless steel and Inconel 718 alloy
}

\author{
Dengyong Wang ${ }^{1,2, *}$, Juchen Zhang ${ }^{3,1}$ \\ ${ }^{1}$ College of Mechanical and Electrical Engineering, Nanjing University of Aeronautics and \\ Astronautics, Nanjing, China \\ ${ }^{2}$ Jiangsu Key Laboratory of Precision and Micro-Manufacturing Technology, Nanjing, China \\ ${ }^{3}$ School of Mechanical Engineering, Hefei University of Technology, Hefei, China \\ *E-mail: wdy15150565695@163.com
}

doi: $10.20964 / 2019.10 .26$

Received: 5 June 2019 / Accepted: 23 July 2019 / Published: 30 August 2019

\begin{abstract}
In Electrochemical machining (ECM), anodic dissolution process is strongly affected by the electrochemical behavior of the target metal. This study aims to improve the counter-rotating electrochemical machining (CRECM) performance of lug boss on Inconel 718 on basis of different dissolution behaviors of metals. The dissolved surfaces of 304 stainless steel and Inconel 718 at various current densities were examined using scanning electron microscope, energy-dispersive X-ray spectroscopy, and electrochemical impedance spectroscopy. The profiles and surface qualities of the machined lug bosses were compared. The results indicated that the 304 stainless steel workpiece presented substantially better machining performance than Inconel 718 due to its favorable localization effect. Straight lug bosses with small fillet radii were fabricated in 304 stainless steel. In contrast, the sidewall of a lug boss formed on the surface of Inconel 718 workpiece was tapered and had a large fillet radius because of substantial corrosion on its top surface. On this basis, a 304 stainless steel coating layer was employed to improve CRECM performance during machining of a high lug boss on Inconel 718 . The experimental results showed that the employment of 304 stainless steel coating layer could prevent the surface of lug boss on Inconel 718 from dissolution and therefore improve the machining accuracy effectively.
\end{abstract}

Keywords: Electrochemical machining; Dissolution behavior; Machining performance; Lug boss; Coating layer

\section{$\underline{\text { FULL TEXT }}$}

(C) 2019 The Authors. Published by ESG (www.electrochemsci.org). This article is an open access article distributed under the terms and conditions of the Creative Commons Attribution license (http://creativecommons.org/licenses/by/4.0/). 